\title{
DAA, 1-BIZ and 5-ATZ as Vapour Phase Corrosion Inhibitors for Mild Steel under Different Aggressive Atmospheric Conditions at High Temperature
}

\author{
Vishal Saini ${ }^{1, *}$, Harish Kumar ${ }^{2}$ \\ ${ }^{1}$ Material Science \& Electrochemistry Laboratory, Department of Chemistry, \\ Chaudhary Devi Lal University, Sirsa, Haryana - 125055, India \\ ${ }^{2}$ Material Science \& Electrochemistry Laboratory, Department of Chemistry, Janta Girls College, \\ Ellenabad, Sirsa, Haryana - 125102, India \\ *E-mail address: dony84@rediffmail.com
}

\begin{abstract}
Mild Steel and their products are main raw material for a strong infrastructure for every country which is the main demand in the race of survival, stabilization, growth and competition. Industrialization and modernization in now a days has made a strong demand of steel and their maintenance but atmospheric corrosion can aggressively accelerate the degradation of steel during their manufacturing, processing, storage and transportation. In these cases, traditional methods to prevent corrosion are not suitable which provide the scope of Vapour Phase Corrosion Inhibitors (VPCI) in industries, defense and daily life. Three new VPCI namely Diallylamine (DAA), 1Benzylimidazole (1-BIZ) and 5-Aminotetrazole (5-ATZ) were tested for mild steel in different aggressive atmospheric conditions by Weight Loss Test, Eschke Test, Salt Spray Test, Sulphur dioxide $\left(\mathrm{SO}_{2}\right)$ Test at $50{ }^{\circ} \mathrm{C}$ and results of these tests were supported by Metallurgical Research Microscopy and Scanning Electron Microscopy (SEM).
\end{abstract}

Keywords: Mild Steel; Weight loss test; Eschke test; Salt spray test; Metallurgical research microscopy; SEM; Vapour phase corrosion inhibitors

\section{INTRODUCTION}

Atmospheric components such as moisture, air pollutants $\left(\mathrm{SO}_{2}, \mathrm{H}_{2} \mathrm{~S}, \mathrm{~N}_{\mathrm{x}} \mathrm{O}_{\mathrm{y}}, \mathrm{CO}_{2}\right.$ and $\mathrm{Cl}^{-}$) and temperature have been reported as corrodents for metal corrosion. Corvo [1] and Moricelli et al. [2] studied the relationship between chloride ion concentrations with the corrosion rate in the atmospheric conditions. Ericsson [3] showed that $\mathrm{NaCl}$ can cause corrosion at very low concentration because it can induce corrosion by $\mathrm{SO}_{2}$ on a carbon steel surface. $\mathrm{NaCl}$ can enhance 14 times rate of corrosion by $\mathrm{SO}_{2}$ at $9 \%$ relative humidity. In an another report of Blucher et al. [4], they have investigated adverse effect of $\mathrm{CO}_{2}$ on corrosion of Al. Vuorinen et al. [5] and a list of authors have worked on the organic compounds as VPCIs. Due to presence of long chain hydrophobic part and the presence of atom having high electron density, organic compounds are the best selection for the compounds used as VPCIs. 
Organic substances have been studied as VPCI for mild steel were morpholine derivatives and diaminohexane derivatives [5], fatty acid thiosemicarbazides [6], cyclohexylamine and dicyclohexylamine [7,8], amine carboxylates [9], ammonium caprylate [10], benzoic hydrazide derivatives [11,12], polyamines [13], bis-piperidiniummethyl-urea and $\beta$-amino alcoholic compounds [14].

Apart from organic substances, natural compounds like wood bark oil [15] and thyme $[16,17]$ have also been used as VPCIs. Cano et al. [18] recently have proposed mechanism of inhibition of dicyclohexamineisonitrite and dicyclohexaminenitrite against corrosion due to vapours of acetic acid and formic acid on carbon steel. Zubielewicz et al. [19] studied the electrochemical behaviour of mixed anodic inhibitors.

Batis et al. [20] evaluated the performance of two primers, first natural rust converter and other on organic primer coating containing VPCI against atmospheric corrosion for reinforcing steel. Lyublinski [21] studied synergistic corrosion management systems by use of corrosion inhibitors. In continuation to our earlier study [22-27], in the present study, the inhibiting properties of Diallylamine (DAA), 1-Benzylamidazole (1-BIZ) and 5Aminotetrazole (5-ATZ) were investigated on mild steel at $85 \%$ relative humidity and $50{ }^{\circ} \mathrm{C}$ by Weight loss test, Salt spray test in a solution of $3.0 \% \mathrm{NaCl}$, Eschke test, $\mathrm{SO}_{2}$ test, Metallurgical research microscopy and Scanning electron microscopy (SEM).

\section{MATERIALS AND METHODS}

Many research papers, articles and reviews have been reported to the study of the techniques used to determine the effectiveness of VPCI against the metallic corrosion such as Adsorption isotherm technique [28], Weight loss technique [29], Potentiodynamic polarization measurements [30], Electrodynamical impedance meseaurment [31], Audioradiography [32] and Capacitance measurments [33].

Tormoen et al. [34] reported three new techniques namely Surface-enhanced Raman spectroscopy, Scanning Kelvin probe microscopy and Contact angle analysis to monitor the adsorption of VPCI on the metallic surface in real time.

These techniques can be used to evaluate the ability of two VPCI to diffuse and adsorb on the surface of metal simultaneously. Materials, equipments and methods used in my present study are explained as below:

\section{1. Material}

Mild steel (ASTM-283) coupons of dimensions $3.5 \mathrm{~cm} \times 1.5 \mathrm{~cm} \times 0.025 \mathrm{~cm}$ and of chemical composition: $\mathrm{C}-0.17, \mathrm{Si}-0.35, \mathrm{Mn}-0.42, \mathrm{~S}-0.05, \mathrm{P}-0.20, \mathrm{Ni}-0.01, \mathrm{Cu}-0.01, \mathrm{Cr}-$ 0.01 and Fe-balance $(w / w)$ were used.

\section{2. Equipments}

\section{2. 1. Weighing Balance}

Single Pan Analytical Balance, Precision 0.01mg, Model AB 135-S/FACT, Source Mettler Toledo, Japan. 


\section{2. 2. Humidity Chamber}

Thermotech TIC-4000N Temperature Controller, Humidity controller with course and fine adjustments, AC Frequeny 50-60 Hz, Max. Voltage $300 \mathrm{~V}$, Source Make-Associated Scientific Tech., New Delhi.

\section{2. 3. Salt Spray Chamber}

Thermotech TIC-4000N Temperature Controller, Pumping system Pt-100, AC Frequeny 50-60 Hz, Max. Voltage $300 \mathrm{~V}$, Source Make-Associated Scientific Tech., New Delhi.

\section{2. 4. Air Thermostat}

Nine adjustable Chambered, Electrically controlled, Accuracy $\pm 0.1{ }^{\circ} \mathrm{C}$.

\section{2. 5. Metallurgical Research Microscope}

CXR II from Laomed, Mumbai, India.

\section{2. 6. Scanning Electron Microscope}

JEOL 5900LV scanning electron microscope. All chemicals used for study were of AR grade with $99 \%$ minimum assay. Along with them triply distilled water (conductivity $<1 \mathrm{x}$ $10^{-6} \mathrm{ohm} / \mathrm{cm}^{-1}$ ) and sulphuric acid were also used.

\section{3. Methods}

\section{3. 1. Vapour Pressure Determination Test}

A standard Knudsen method was used to determine the vapour pressure of all the investigated VPCIs. For this purpose, definite amount of exactly weighed VPCI was placed in a single neck round bottom flask fitted with a rubber cork in the neck having a glass capillary of $1.0 \mathrm{~mm}$ diameter in the center of rubber cork. Then the flask was kept in electrically controlled air thermostat maintained at the constant temperature of $50{ }^{\circ} \mathrm{C}$ for 10 days. Change in the weight of VPCIs was observed by analytical balance and the vapour pressure of the investigated VPCI was determined by the weight loss of VPCI for the time of exposure by equation-1.

$$
P=\left[\frac{W}{A t}\left[\frac{2 \pi R T}{M}\right]^{1 / 2}\right]
$$

where; $P=$ vapour pressure of the VPCI $(\mathrm{mmHg}), A=$ area of the orifice $\left(\mathrm{m}^{2}\right), t=$ time of exposure (sec.), $W=$ weight loss of VPCI $(\mathrm{kg}), T=$ temperature $(\mathrm{K}), M=$ molecular mass of the inhibitor $(\mathrm{kg})$ and $R=$ gas constant $\left(8.314 \mathrm{JK}^{-1} \mathrm{~mol}^{-1}\right)$.

\section{3. 2. Weight Loss Test}

Mild steel coupons were mechanically polished successively with the help of emery papers of grading 100, 200,300, 400 and $600 \mu$ and then thoroughly cleaned with plenty of triple distilled water, ethanol and acetone. Then coupons were dried with hot air blower and 
stored in desiccators over silica gel. Weight loss tests were carried out in an electronically controlled air thermostat maintained at a constant temperature of $50{ }^{\circ} \mathrm{C}$ with in an accuracy of $\pm 0.1^{\circ} \mathrm{C}$. After recording the initial weights of mild steel coupons, they were kept in different isolated chambers of air thermostat having fixed amount of VPCI at a constant temperature of $50{ }^{\circ} \mathrm{C}$ for 24 hours of exposure time. A uniform thin film of VPCI was adsorbed onto the metal coupon after 24 hours of exposure. Then these coupons were transferred to a digitally controlled humidity chamber maintained at $85 \%$ humidity at a constant temperature of $50{ }^{\circ} \mathrm{C}$ for 10 days. Blank coupons untreated with VPCI were also kept in the humidity chamber for the same duration in the same corrosive environment. After exposing the coupons for 10 days, coupons were taken out from the humidity chamber and washed initially under the running tap water. Loosely adhering corrosion products were removed with the help of rubber cork and coupon was again washed thoroughly with triple distilled water and dried with hot air blower and then weighed again. Corrosion rate in mils per year (mpy) and percentage corrosion inhibition efficiency (PCIE) were calculated by using the equation-2 and equation3 respectively.

$$
\text { Corrosion Rate }(\mathrm{mpy})=\frac{534 X \mathrm{~W}}{D A T}
$$

where, $\mathrm{W}=$ weight loss (in $\mathrm{mg}$ ), $\mathrm{D}=$ density of mild steel (in $\mathrm{g} / \mathrm{cm}^{3}$ ), $\mathrm{A}=$ area of coupon (in sq. inch), $\mathrm{T}=$ exposure time (in hour).

$$
\text { Percentage Inhibition Efficiency }=\frac{C R o-C R}{C R o} X 100
$$

where, $\mathrm{CR}_{\mathrm{o}}=$ corrosion rate in absence of inhibitor and $\mathrm{CR}=$ corrosion rate in presence of inhibitor.

\section{3. 3. Salt Spray Test}

After exposing the pre weighed mild steel coupons to VPCI in air thermostat for 24 hours, they were transferred to salt spray chamber having $3.0 \%$ sodium chloride solution maintained at $50{ }^{\circ} \mathrm{C}$ for duration of 10 days along with blank coupons. After exposing the coupons for 10 days, coupons were treated in same manner as treated in weight loss test to remove corrosion products and then $\mathrm{CR}$ and PCIE were calculated.

\section{3. 4. Eschke Test}

Eschke test was carried out the pre-weighed mechanically polished mild steel coupons as prescribed in the literature. Kraft papers of suitable size were dipped in the VPCI for 30 seconds and then dried to adsorb uniform layer of the inhibitor on the Kraft papers. Mild steel coupons were wrapped in VPCI impregnated Kraft papers and then taken in the humidity chamber maintained at $85 \%$ relative humidity maintained at $50{ }^{\circ} \mathrm{C}$ for first 12 hours and 25 ${ }^{\circ} \mathrm{C}$ for next 12 hours alternately for 10 days. This temperature cycle was maintained in two sets because of formation and condensation of vapours of VPCI on mild steel surface regularly. After exposing the coupons for 10 days, coupons were treated in same manner as treated in weight loss test to remove corrosion products and then CR and PCIE were calculated. 


\section{3. 5. Sulphurdioxide Test}

$\mathrm{SO}_{2}$ test was carried out on the mild steel coupons as in weight loss test. $\mathrm{SO}_{2}$ gas was prepared by dissolving $0.04 \mathrm{~g}$ of sodium thiosulphate in $30 \mathrm{~mL}$ aqueous solution of $1.0 \%$ $\mathrm{NH}_{4} \mathrm{Cl}$ and $1.0 \% \mathrm{Na}_{2} \mathrm{SO}_{4}$ solution and $0.5 \mathrm{~mL}$ of $1.0 \mathrm{~N} \mathrm{H}_{2} \mathrm{SO}_{4}$ was added to the flask. Initially pre-weighed and mechanically polished mild steel coupons were placed in air thermostat maintained at $50{ }^{\circ} \mathrm{C}$ for duration of 10 days. Definite weight of VPCIs in a petridis and the flask, which is the source of $\mathrm{SO}_{2}$, were placed in the isolated chambers of air thermostat containing mild steel coupons. After exposing the coupons for 10 days, coupons were treated in same manner as treated in weight loss test to remove corrosion products and then CR and PCIE were calculated.

\section{3. 6. Metallurgical Research Microscopy}

This test was employed to know about nature and type of corrosion using metallurgical research microscope. To investigate the corrosion inhibition efficiency of investigated VPCIs, micrographs of the corroded coupons treated with investigated VPCI were subjected to porosity study and morphology of surface. By the obtained results a comparative study of that porosity and surface morphology was carried which provided the information about the number of pores, size of pores, percentage porosity and the area covered by the pores on the surface of coupon after the four different corrosion experiments. Percentage porosity (PP) and total objects (TO) shows the roughness of surface. On the other hand maximum perimeter and maximum area object ratio $(\mathrm{A} / \mathrm{O})$ provide the information about the size and depth of the pores on the surface of mild steel after the corrosion test. Micrographs of the blank corroded coupons were taken after exposure of different aggressive environments for 10 days are shown in Table 1. Results of metallurgical research microscopy of blank mild steel coupon after different corrosion tests are reported in Table 2. From Table 2, it is clear that in weight loss test, 9774 pores cover $8886066.4820 \mu^{2}$ area due to uniform corrosion in humid environment by which $68.90 \%$ surface become porous. In this test, numbers of pores are very high but $\mathrm{A} / \mathrm{O}$ ratio is not very high as compared to that of salt spray test. In salt spray test, percentage porosity (69.94\%) is almost equal to that of weight loss test but the numbers of pores $(13,380)$ and the porous area $\left(1096879.5014 \mu^{2}\right)$ on the mild steel surface are high due to corrosive action of direct exposure of chloride ions on the surface of mild steel coupon. In this test, perimeter of pore $(52323.4375 \mu)$ and $\mathrm{A} / \mathrm{O}$ ratio are high due to large size and high depth of pores respectively.

Table 1. Micrographs of blank mild steel coupon in different corrosion tests.

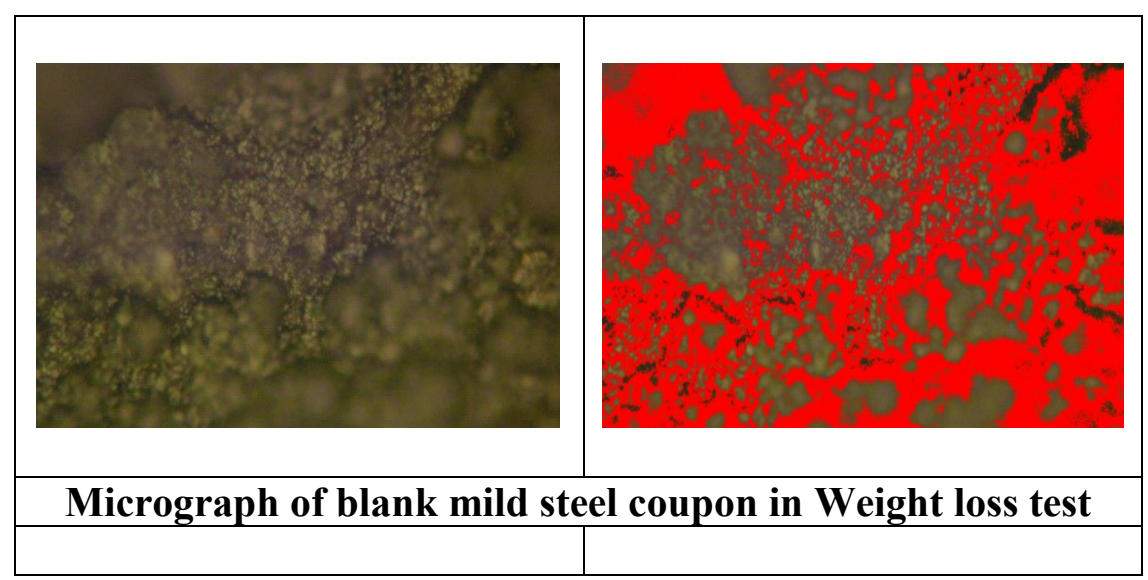




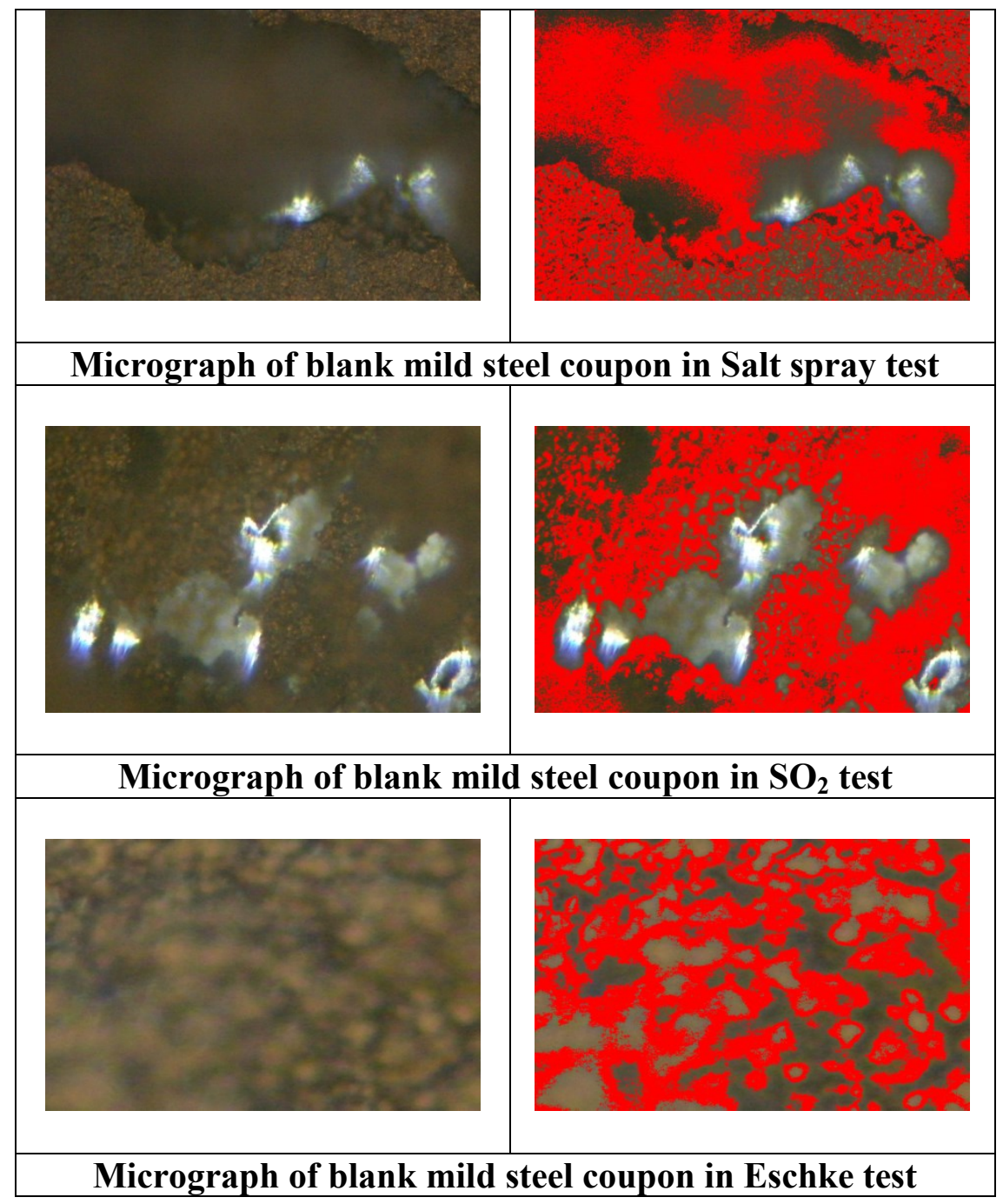

In $\mathrm{SO}_{2}$ test, although the numbers of pores (3783) are very low as compared to other corrosion experiments yet the percentage porosity $(86.52 \%)$ are highest in this test. In this test the size of pores $(78541.5913 \mu)$ and $\mathrm{A} / \mathrm{O}$ ratio are very high due to high depth of the pores by the acidic action of $\mathrm{SO}_{2}$ environment which provide evidence in favour of mechanism of pits formation on the surface of coupon by the acidic action of $\mathrm{SO}_{2}$. In Eschke test, depth of pores is very low due to small size of pore of perimeter $(20138.1682 \mu)$ but total objects (6448) are high due to roughness of surface by the action of corrodents of environment.

Table 2. Micrograph results of blank mild steel coupon in different corrosion tests.

\begin{tabular}{|c|c|c|c|c|}
\hline & TO & PP & MP $(\boldsymbol{\mu})$ & MA $\left(\boldsymbol{\mu}^{2}\right)$ \\
\hline Weight Loss Test & 9774 & 68.9 & 55805.5407 & 8886066.4820 \\
\hline Salt Spray Test & 13380 & 69.94 & 52323.4375 & 1096879.5014 \\
\hline
\end{tabular}




\begin{tabular}{|c|c|c|c|c|}
\hline SO$_{2}$ Test & 3783 & 86.62 & 78541.5913 & 9770443.2133 \\
\hline Eschke Test & 6448 & 69.11 & 20138.1682 & 4461322.7147 \\
\hline
\end{tabular}

\section{3. 7. Scanning Electron Microscopy}

This technique gives the morphology study of mild steel coupons after treatment of different corrosion tests which provide the evidences in the support of inhibition data of investigated VPCIs, type of corrosion and for the mechanism of inhibition. In this technique, the coupons, after treating with the different tests, were studied at different resolutions on the different spots on the mild steel coupons for complete information about the inhibition mechanism. SEM of the blank mild steel coupons were also taken for the comparative study of metal specimens which are given in Figure 1.
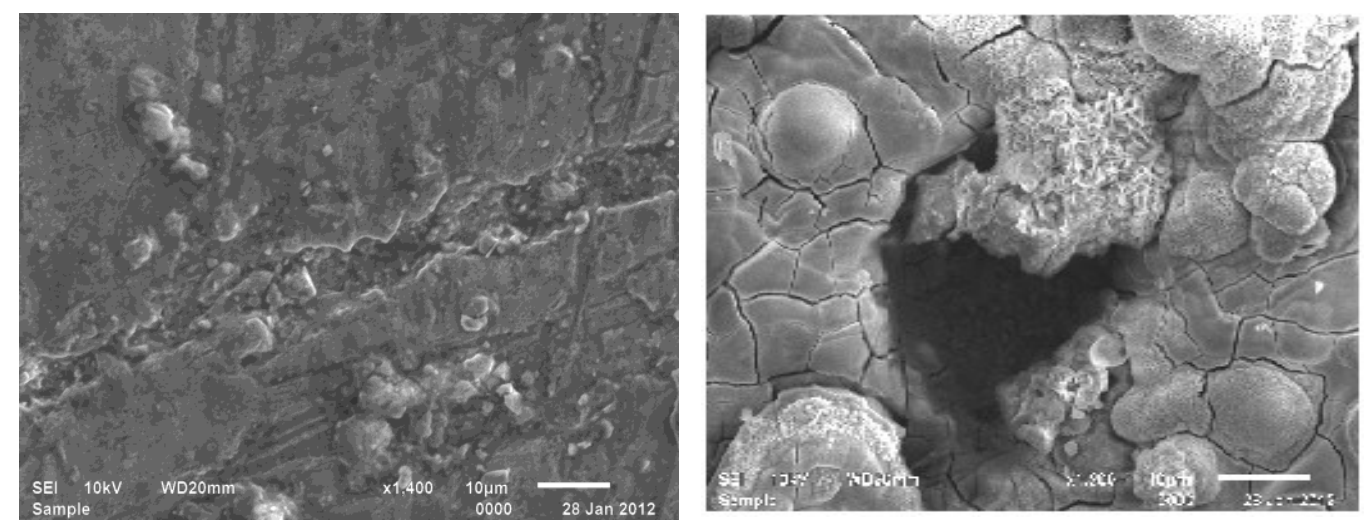

Figure 1. Scanning electron micrographs of blank mild steel coupons.

Micrographs of the blank coupons clearly provide the evidence of the pitting and crevice corrosion in corroding environments.

\section{RESULTS AND DISCUSSION}

\section{1. Vapour Pressure Determination Test}

Results of vapour pressure determiniation test for investigated vapour phase corrosion inhibitors are given in Table 3.

Table 3. Vapour pressure of investigated VPCIs.

\begin{tabular}{ccc}
\hline S. No. & Inhibitors & Vapour Pressure (mmHg) \\
1. & DAA & $367.70 \times 10^{-2}$ \\
2. & $1-\mathrm{BIZ}$ & $150.27 \times 10^{-3}$ \\
3. & $5-\mathrm{ATZ}$ & $113.62 \times 10^{-3}$ \\
\hline
\end{tabular}


Due to presence of sufficient vapour pressure, vapours of investigated VPCIs can easily adsorbed on the surface of mild steel coupon and form a barrier film for water vapours and corrosive aggressive contents of atmosphere around the coupons and protect coupons from corrosion by the formation of protective layer.

\section{2. Weight Loss Test}

The values of CR and PCIE for investigated VPCIs obtained by weight loss test at 50 ${ }^{\circ} \mathrm{C}$ are summarized in Table 4.

Table 4. Weight loss test parameters obtained for VPCIs at $50{ }^{\circ} \mathrm{C}$ temperature and $85 \%$ Relative humidity for 10 days for mild steel coupons.

$\begin{array}{llccc}\text { S. No. } & \text { VPCI } & \text { Weight Loss(mg) } & \text { CR (mpy) } & \text { PCIE } \\ \text { 1. } & \text { Blank } & 14.8 & 5.12 & - \\ \text { 2. } & \text { DAA } & 0.9 & 0.31 & 93.92 \\ \text { 3. } & \text { 1-BIZ } & 5.3 & 1.79 & 64.90 \\ \text { 4. } & \text { 5-ATZ } & 5.8 & 2.00 & 60.78\end{array}$

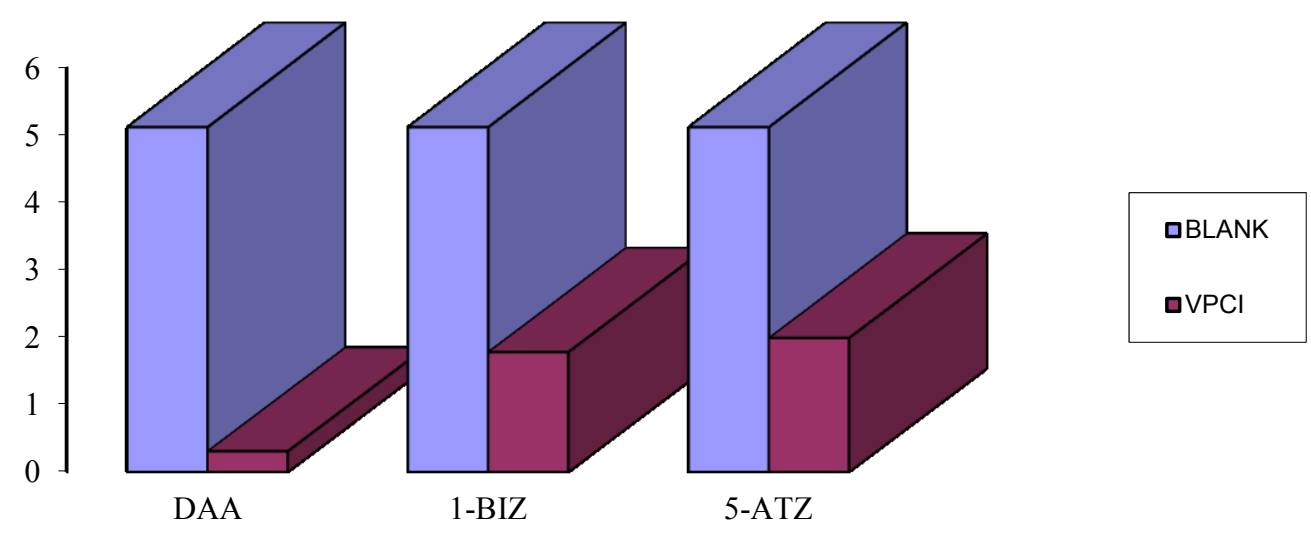

Figure 2. CR of mild steel coupons treated with different VPCI with respect to blank coupons obtained from Weight loss test.

CR of mild steel treated with investigated VPCIs are given in Figure 2 form which it is clear that the CR is negligible in the coupons of mild steel which were treated with DAA. In present study, DAA shows highest (93.92\%) PCIE for the mild steel under the atmospheric conditions at $50^{\circ} \mathrm{C}$. It is clear from the data given in the Table 4, Figure 2 and Figure 3 that all investigated VPCIs have good PCIE can be used to prevent the corrosion of mild steel under aggressive atmospheric conditions at high temperature. 


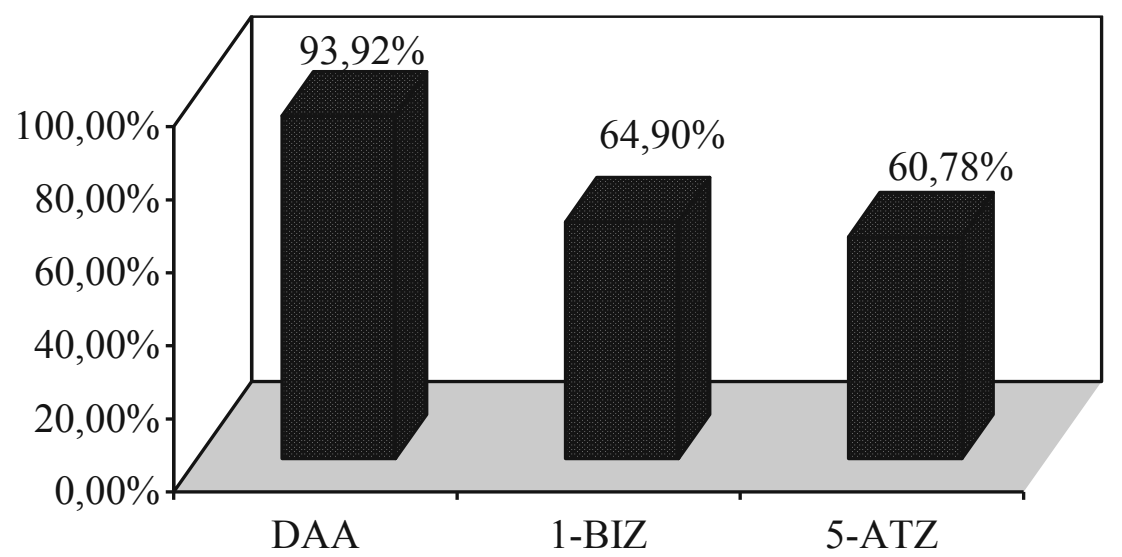

Figure 3. PCIE of different VPCIs obtained from Weight loss test.

\section{3. Salt Spray Test}

After 10 days duration of salt spray test, mild steel coupons were collected and weight loss of mild steel coupons treated with various VPCIs were noted from which CR and PCIE were calculated for investigated VPCIs. Results of weight loss and CR of mild steel after exposure of $\mathrm{NaCl}$ at $50^{\circ} \mathrm{C}$ are shown in Figure 4.

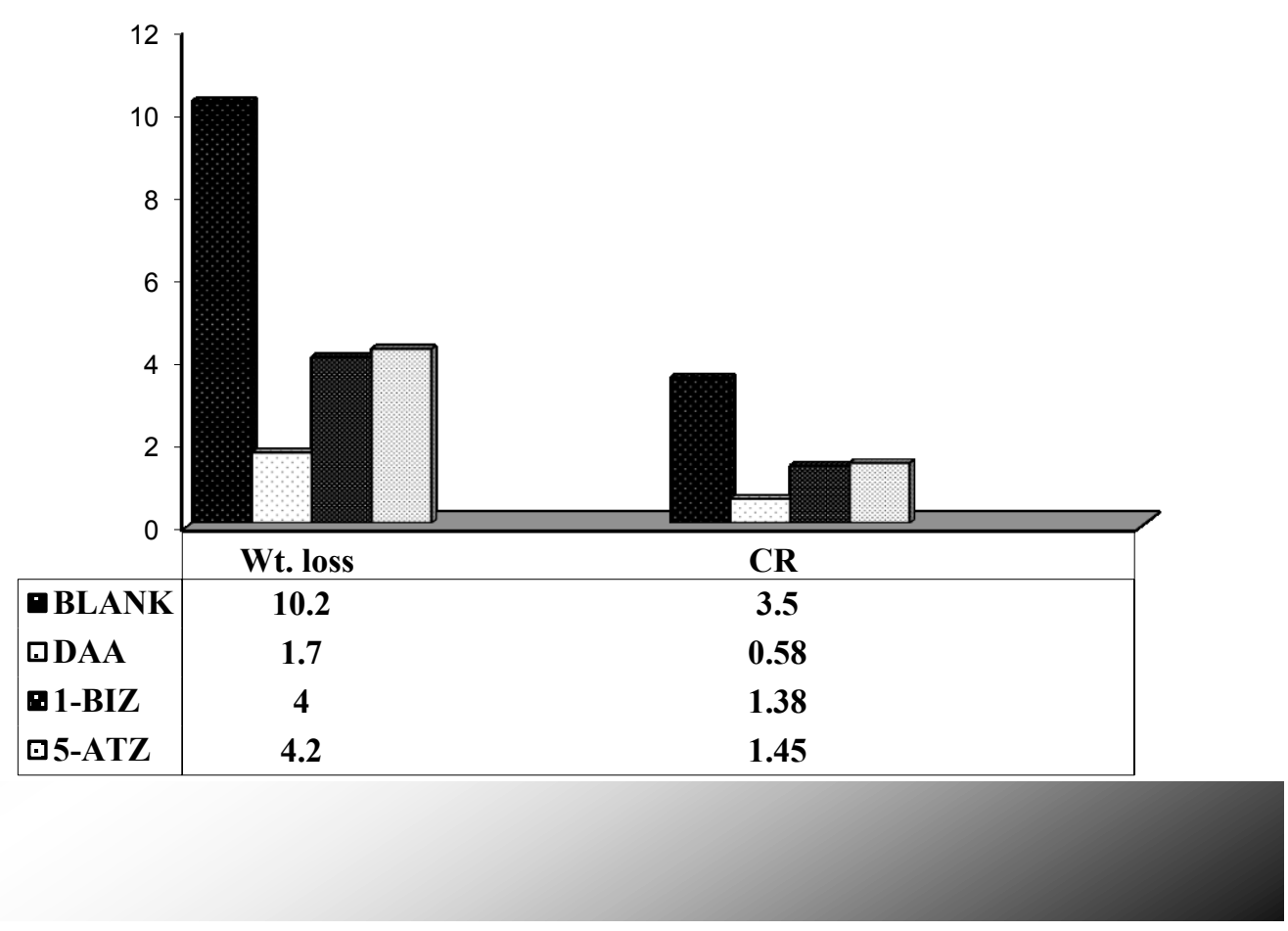

Figure 4. Weight loss and CR of mild steel coupons treated with VPCIs obtained from Salt spray test. 


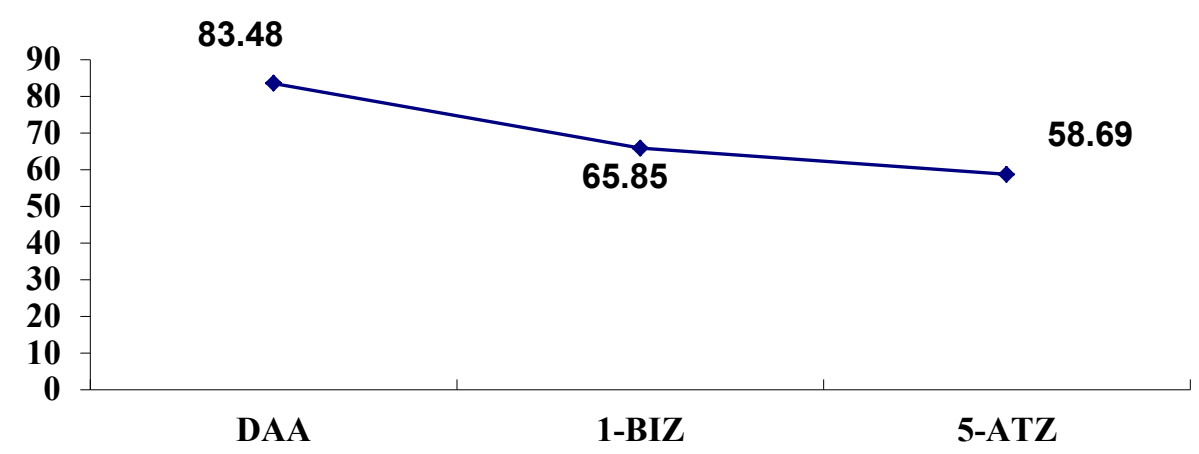

Figure 5. PCIE of VPCIs obtained from Salt spray test.

It is clear from Figure 4 that in salt spray test, direct contact of chloride ions on mild steel coupons accelerate the rate of corrosion due to which corrosion rate of mild steel coupon treated with DAA (0.58) is higher in salt spray test than the corrosion rate of coupon treated with DAA (0.31) in weight loss test as shown in Table 4. From Figure 5, it is shown that all investigated VPCIs were worked very well against the salt spray at high temperature.

\section{4. Eschke Test}

Weight loss of the mild steel coupons, CR and PCIE of various VPCIs were calculated at $50{ }^{\circ} \mathrm{C}$ for the duration of 10 days in Eschke test and the data obtained are shown in Figure 6 and Figure 7. It is clear from the Figure 6 that DAA perform very significant role against the corrosion at atmospheric conditions at high temperature. The visual observations of the mild steel coupons are also given in Table 5.

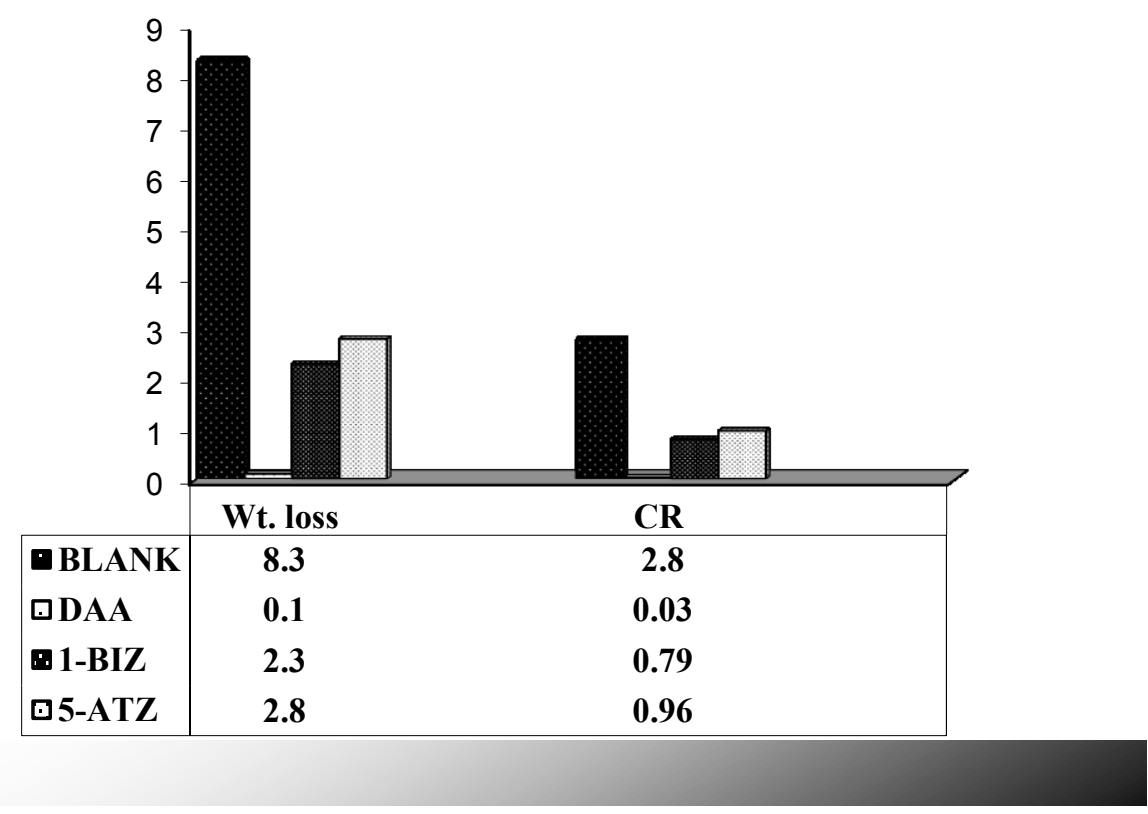

Figure 6. Weight loss and CR of mild steel coupons treated with VPCIs obtained from Eschke test. 


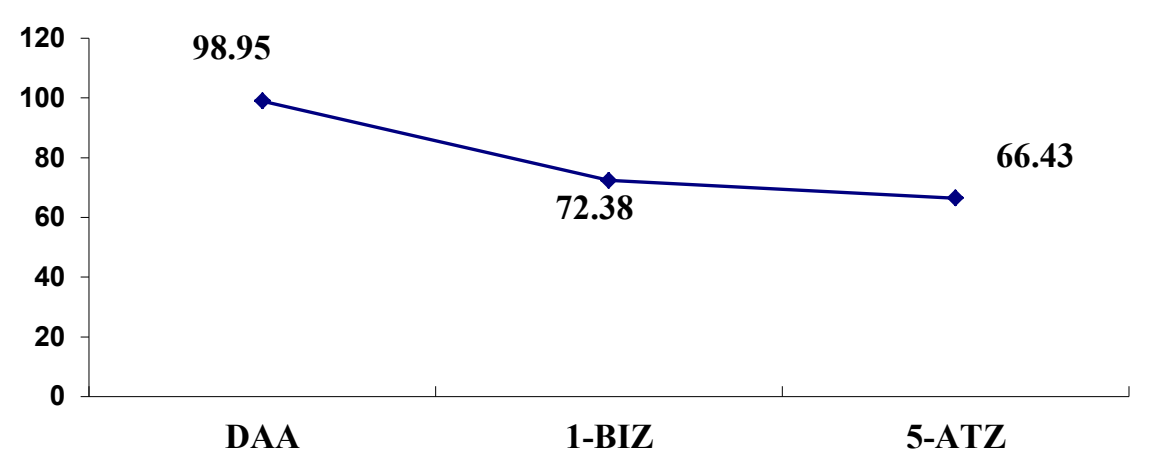

Figure 7. PCIE of VPCIs obtained from Eschke test.

\section{5. $\mathrm{SO}_{2}$ Test}

Results obtained for different corrosion determination parameters by $\mathrm{SO}_{2}$ test are given in Figure 8 and Figure 9.

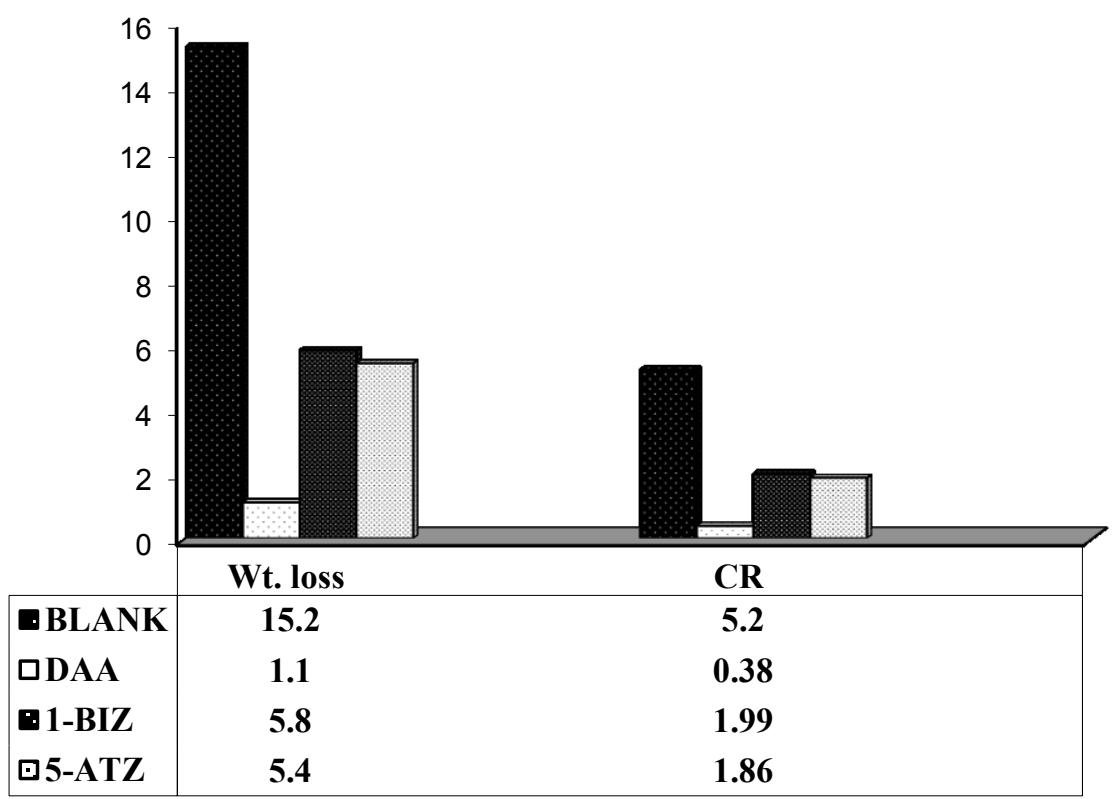

Figure 8. Weight loss and $\mathrm{CR}$ of mild steel coupons treated with VPCIs obtained from $\mathrm{SO}_{2}$ test.

It is seen that the value of CR of mild steel coupons treated with VPCIs is high in this test for the same duration as compared with $\mathrm{CR}$ in Eschke test due to the acidic environment of $\mathrm{SO}_{2}$. from Figure 9 it is shown that the entire investigated VPCIs play significant role to prevent the mild steel from the corrosion in acidic environment of $\mathrm{SO}_{2}$ which is the part of the atmospheric gases near the industries. Visual observations of mild steel coupons treated in $\mathrm{SO}_{2}$ test is also given in Table 6. 


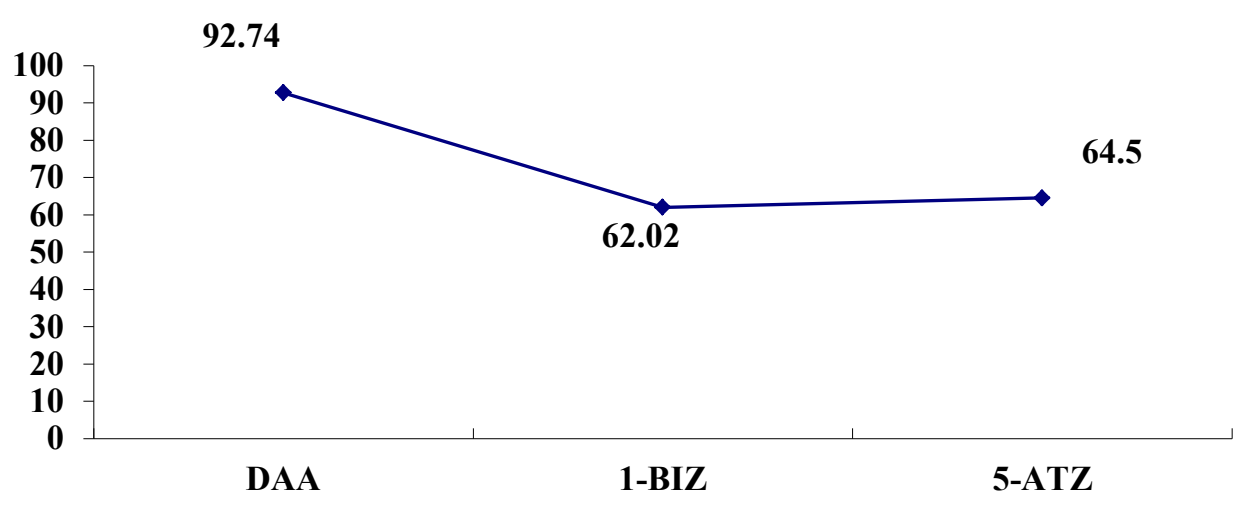

Figure 9. PCIE of VPCIs obtained from $\mathrm{SO}_{2}$ test.

Table 6. Visual observations of mild steel coupons surface after performed various tests.

\begin{tabular}{clll}
\hline VPCI & Salt Spray Method & Eschke Test & $\mathbf{S O}_{2}$ Test \\
Blank & clear pits were visible & uniform corrosion & pitting corrosion \\
DAA & $\begin{array}{l}\text { Clean surface } \\
\text { No corrosion product }\end{array}$ & $\begin{array}{l}\text { clean surface } \\
\text { No corrosion product }\end{array}$ & $\begin{array}{l}\text { clean surface } \\
\text { No corrosion } \\
\text { product }\end{array}$ \\
1-BIZ & slightly tarnishing & almost clean surface & slightly tarnishing \\
5-ATZ & slightly tarnishing & almost clean surface & slightly tarnishing \\
\hline
\end{tabular}

\section{6. Metallurgical Research Microscopy}

\section{6. 1. Metallurgical Research Microscopy of DAA}

Results of metallurgical research microscopy of mild steel coupons treated with DAA after different corrosion tests are reported with micrographs of mild steel coupon in Table 7. In micrograph, red coloured area is the porous surface selected for the surface study by the help of trinocular inverted metallurgical research microscope. By comparison of the data obtained by different corrosion tests, it is clear that percentage porosity is significantly low in all tests due to good inhibition action of DAA against the atmospheric corrosion. In weight loss test, 112 pores cover $310.4183 \mu^{2}$ area due to uniform corrosion in humid environment by which $0.3 \%$ surface become porous. In weight loss test $\mathrm{A} / \mathrm{O}$ ratio is very high due to depth of pore of perimeter $109.9928 \mu$. In $\mathrm{SO}_{2}$ test, the numbers of pores are relatively high 
(636) as compared to weight loss test but there is little difference in percentage porosity which is due to acid neutralizing action of DAA. A/O ratio of this test is very low due to only roughness of mild steel surface. Micrographs of all tests show that almost smooth surface without any corrosion products are obtained of mild steel coupon after the treatment of coupon with DAA.

Table 7. TO, PO, MP of pore and MA covered by pore on mild steel coupon after treated with DAA after different corrosion tests.

\begin{tabular}{|c|c|c|c|c|c|}
\hline & TO & PP & $\mathbf{M P}(\mu)$ & MA $\left(\mu^{2}\right)$ & Micrograph \\
\hline $\begin{array}{c}\text { Weight Loss } \\
\text { Test }\end{array}$ & 112 & 0.3 & 109.9928 & 310.4183 & \\
\hline $\begin{array}{c}\text { Salt Spray } \\
\text { Test }\end{array}$ & 1063 & 14.97 & 287.1189 & 967.2853 & \\
\hline $\mathrm{SO}_{2}$ Test & 636 & 0.72 & 77.6387 & 83.7494 & \\
\hline Eschke Test & 362 & 0.15 & 89.1421 & 110.8033 & \\
\hline
\end{tabular}

\section{6. 2. Metallurgical Research Microscopy of 1-BIZ}

Results of metallurgical research microscopy of mild steel coupon treated with 1-BIZ after four different corrosion tests are reported with micrographs in table 8. By comparison of the data obtained by four different corrosion tests, it is clear that percentage porosity is significantly low as compared to blank coupon in all tests due to good inhibition action of 1BIZ against the atmospheric corrosion In weight loss test, 1379 pores cover $1592.7928 \mu^{2}$ area due to uniform corrosion in humid environment by which $15.89 \%$ surface become porous.

In salt spray test and $\mathrm{SO}_{2}$ test, numbers of pores (954 and 2867) are low but perimeter of pores $(2857.8262 \mu$ and $2392.6668 \mu)$ and A/O ratio are very high due to large size and high depth of pores respectively. 
Table 8. TO, PO, MP of pore and MA covered by pore on mild steel coupon after treated with 1-BIZ after different corrosion tests.

\begin{tabular}{|c|c|c|c|c|c|}
\hline & TO & PP & MP( $\boldsymbol{\mu})$ & MA $\left(\boldsymbol{\mu}^{2}\right)$ & Micrograph \\
\hline $\begin{array}{c}\text { Weight } \\
\text { Loss Test }\end{array}$ & 1379 & 15.89 & 1688.9461 & 1592.7978 & \\
\hline $\begin{array}{c}\text { Salt } \\
\text { Spray } \\
\text { Test }\end{array}$ & 954 & 14.71 & 2857.8262 & 2872.9166 & \\
\hline $\begin{array}{c}\text { SO } \\
\text { Test }\end{array}$ & 2867 & 18.79 & 2392.6668 & 6634.3490 & \\
\hline $\begin{array}{c}\text { Test } \\
\text { Eschke }\end{array}$ & 6063 & 9.70 & 213.7539 & 558.1717 & \\
\hline
\end{tabular}

In Eschke test, depth of pores is comparatively low due to small size of pore of perimeter $213.7539 \mu$ but total objects (6063) are high due to roughness of surface by the action of corrodents of environment.

Micrographs of all tests show that almost smooth surface without any corrosion products are obtained of mild steel coupon after the treatment of coupon with 1-BIZ.

\section{6. 3. Metallurgical Research Microscopy of 5-ATZ}

Results of metallurgical research microscopy of mild steel coupon treated with 5-ATZ after different corrosion tests are reported with micrographs of mild steel coupon in Table 9.

In weight loss test, 1556 pores cover $3127.6814 \mu^{2}$ area due to uniform corrosion in humid environment by which $19.17 \%$ surface become porous.

In salt spray test, percentage porosity $(20.74 \%)$ is high but numbers of pores (1402) are low due to direct spray of salt on surface of coupon. In this test, perimeter of pore $(1896.8319 \mu)$ and $\mathrm{A} / \mathrm{O}$ ratio are very high due to large size and high depth of pores respectively. 
Table 9. TO, PO, MP of pore and MA covered by pore on mild steel coupon after treated with 5ATZ after different corrosion tests.

\begin{tabular}{|c|c|c|c|c|c|}
\hline & TO & $\mathbf{P P}$ & $\mathbf{M P}(\mu)$ & MA $\left(\mu^{2}\right)$ & Micrograph \\
\hline $\begin{array}{c}\text { Weight } \\
\text { Loss Test }\end{array}$ & 1556 & 19.17 & 1077.8876 & 3127.6814 & \\
\hline $\begin{array}{c}\text { Salt Spray } \\
\text { Test }\end{array}$ & 1402 & 20.74 & 1896.8319 & 5483.7950 & \\
\hline $\mathrm{SO}_{2}$ Test & 502 & 15.41 & 12870.4577 & 1390.5817 & \\
\hline $\begin{array}{c}\text { Eschke } \\
\text { Test }\end{array}$ & 1288 & 13.01 & 725.6568 & 2639.9668 & \\
\hline
\end{tabular}

In $\mathrm{SO}_{2}$ test, although numbers of pores (502) are significantly very low as compared to weight loss test and salt spray test due to its percentage porosity $(15.41 \%)$ but in this test perimeter of pores $(12870.4577 \mu)$ are high due to very large pores as compared to weight loss test.

In Eschke test, depth of pores is comparatively low due to small size of pore of perimeter $725.6568 \mu$ and of high total objects (1288). These parameters show significantly low percentage porosity $(13.01 \%)$ in this test.

\section{7. Scanning Electron Microscopy}

By comparison of SEM images of the mild steel coupons treated with VPCI with SEM images of blank coupons as shown in Table 10, it is clear that all VPCIs show very excellent corrosion inhibition properties against the aggressive environments. The SEM images of the mild steel coupons with their observations are given in Table 10. 
Table 10. SEM images of mild steel coupons treated with DAA, 1-BIZ and 5-ATZ after corrosion tests.

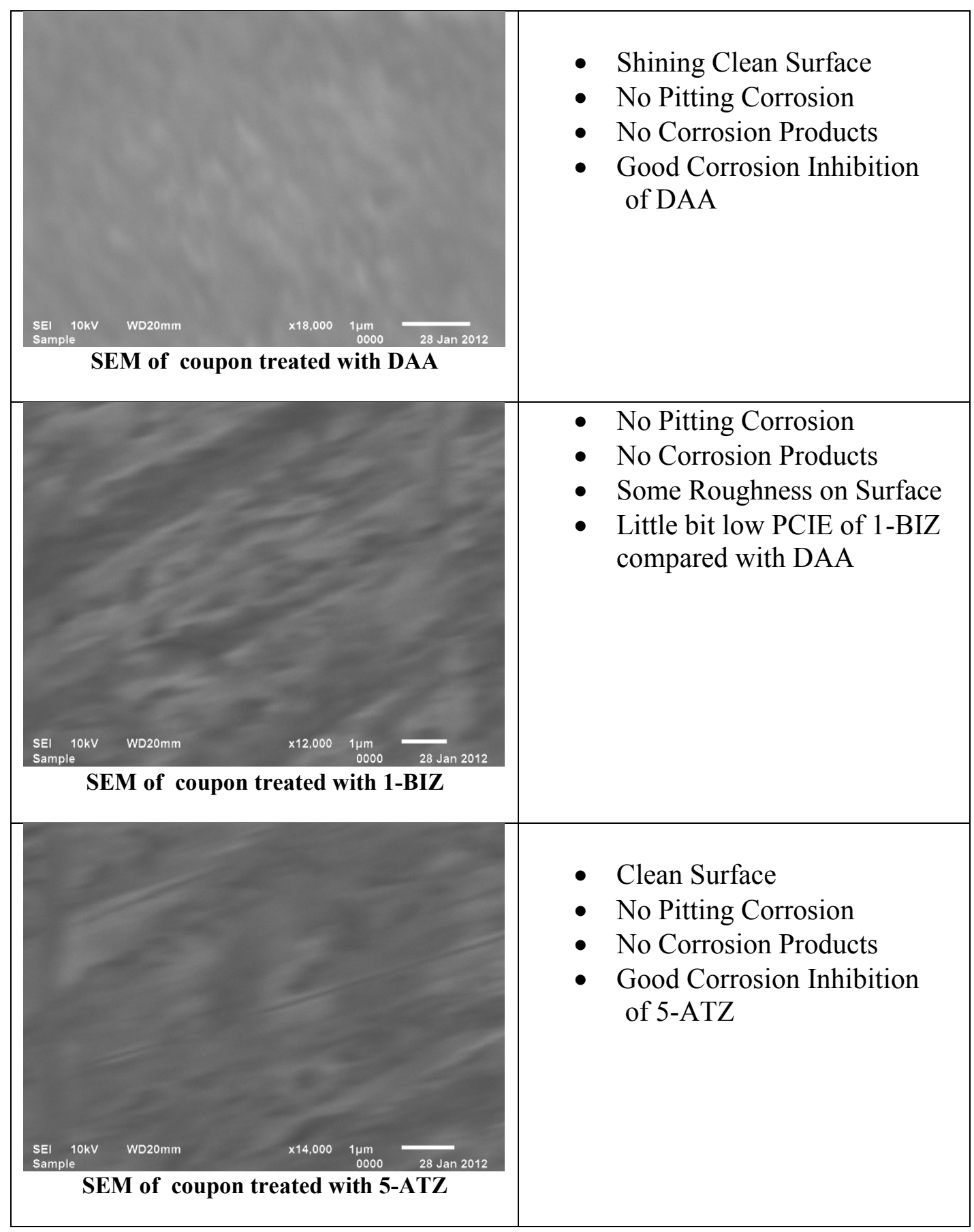

\section{8. Mechanism of Inhibition}

As a result of experimental work carried out on the performance of investigated vapour phase corrosion inhibitors, a deep analysis of corrosion parameters obtained by corrosion testing experiments, morphology of mild steel coupon studied with the help of metallurgical research microscopy and scanning electron microscopy has reveled that the probable mechanism of inhibition action of investigated VPCIs contains the following features: 
a) Due to sufficient vapour pressure of DAA, it saturates the environment around the metal and due to high vapour density than air and water it excludes the water vapours and aggressive contents in atmosphere around the surface of metal and adsorbed itself on the surface and protects the metal from corrosion.

b) The presence of lone pair donar $\mathrm{N}$ atoms provide it specific groups by which it can be easily adhere on the surface of metal.

c) Presences of two allyl groups, at terminal positions, provide the $\pi$-electron system which help DAA to form the barrier film on the metallic surface against the corrosive action of the aggressive contents of atmosphere.

d) Presence of methylene group near the lone pair donar atom enhances the basic strength of the DAA due to + I effect.

e) Presence of two amine groups having lone pair donar $\mathrm{N}$ atoms in the molecule of 1BIZ which provide the ability to adsorb on the surface of metal to protect it from corrosive environments.

f) Presence of methylene group near the lone pair donar atom enhances the electron density of $\mathrm{N}$ atom and basic strength of 1-BIZ by inductive effect.

g) Presence of benzene ring provides $\pi$-electrons systems which make 1-BIZ as a good surfactant to show inhibition action against corrosion.

h) Presence of many lone pair donar $\mathrm{N}$ atoms, $\pi$-electrons of unsaturation and one free amine group in the molecule of 5-ATZ provide the ability to adsorb on the surface of metal to protect it from corrosive environments.

i) Presence of alternative double bond and unsaturation near the lone pair donar atom make PCIE of inhibitor low due to resonating stabilization.

j) Presence of high electron density due to electronic repulsion provides high basic strength to neutralize the acidic environment in $\mathrm{SO}_{2}$ test. The condition make the high $\mathrm{PCIE}$ of 5-ATZ in aggressive corrosive environment in $\mathrm{SO}_{2}$ test.

\section{CONCLUSIONS}

From the results of Weight Loss, Salt Spray, Eschke test and Metallurgical research microscopy amd SEM, the following conclusion can be drawn:

a) All investigated VPCIs show high percentage corrosion inhibition property toward mild steel in different corrosive environment like high relative humidity, $3.0 \%$ sodium chloride, $\mathrm{SO}_{2}$ gas and high temperature $\left(50^{\circ} \mathrm{C}\right)$.

b) DAA shows high corrosion inhibition efficiency in different corrosive environment due to sufficient vapour pressure of DAA.

c) VPCIs saturate the space with their vapors and reducing the relative humidity below critical value and also alkalize the medium to a higher $\mathrm{pH}$ value at which the rate of corrosion become significantly low.

d) Percentage corrosion inhibition efficiency was found to be in the order DAA $>1$-BIZ $>5$-ATZ.

e) It was observed that presence of alternative double bond and unsaturation near the lone pair donar atom make PCIE of inhibitor low due to resonating stabilization in 1BIZ and 5-ATZ. 
f) Results obtained from Weight Loss technique, Eschke test, Salt Spray method are in good agreement with each other inspite of different corrosive environment and are further supported by surface study carried out by SEM technique.

\section{Acknowlegment}

We are very thankful to University Grant Commission, New Delhi for provide us financial support and Ch. Devi Lal University and Janta Girls College for laboratory and equipments facility for this research work.

\section{References}

[1] Corvo F., Corros. 40 (1984) 4.

[2] Morcillo M., Chico B., Otero E., Mariaca L., Mater. Perf. 38(4) (1999) 24.

[3] Ericsson R., Werks. Korros. 29 (1978) 400.

[4] Blucher B. D., Lindstrom R., Svensson J. E., Johansson L. G., J. Electrochem. Soc. 148 (2001) 127.

[5] Vuorinen E., Ngobeni P., Van der Klashorst G. H., Skinner W., De W. E., Ernst W. S., Brit. Corros. J. 29 (1994) 120.

[6] Quraishi M. A., Jamal D., Singh R. N., Corros. 58 (2002) 201.

[7] Subramanian A., Kumar R. R., Natesan M., Vasudevan T., ACMM 49 (2002) 354.

[8] Subramanian A., Rajendran P., Natesan M., Balakrishnan K., Vasudevan M., ACMM 46 (1999) 346.

[9] Vuorinen E., Skinner W., Brit. Corros. J. 37 (2002) 159.

[10] Skinner W., Preez F. D., Vuorinen E., Brit. Corros. J. 34 (1999) 151.

[11] Quraishi M. A., Jamal D., Metall. and Mater. Sci. 47 (2005) 45.

[12] Quraishi M. A., Bhardwaj V., Jamal D., Ind. J. Chem. Tech. 12 (2005) 39.

[13] Zhang D. Q., Gao L. X., Zhou G. D., Mater. and Corros. 58 (2007) 594.

[14] Khamis E., Andis N. A., Material Wissenschaft and Werkstoff technik 33 (2002) 550.

[15] Poongothai N., Rajendran P., Natesan M., Palaniswamy N., Ind. J. Chem. Tech. 12 (2005) 641.

[16] Premkumar P., Kannan K., Natesan M., Asian J. Chem. 20 (2008) 445.

[17] Premkumar P., Kannan K., Natesan M., J. Metall. and Mater. Sci. 50 (2008) 227.

[18] Cano E., Bastidas D. M., Simancas J., Bastidas J. M., Corros. 61 (2005) 473.

[19] Zubielewicz M., Gnot W., Progr. In Organ. Coating. 49 (2004) 358.

[20] Batis G., Kouloumbi N., Soulis E., Anti Corros. Meth. and Mat. 45(4) (1998) 222.

[21] Lyublinski E. Y., Synergistic Corrosion Management Systems for Controlling, Eliminating and Managing Corrosion. WO patent 124058, (2008).

[22] Kumar H., Saini V., Yadav V., Int. J. Eng. \& Innovative Tech. 3(3) (2013) 206-211. 
[23] Kumar H., Yadav V., Am. J. of Materials Sci. \& Eng. 1(3) (2013) 34-39.

[24] Kumar H., Yadav V., J. Corros. Sci. \& Eng. 16(4) (2013).

[25] Kumar H., Saini V., J. Corros. Sci. \& Eng. 14(5) (2012).

[26] Kumar H., Saini V., Res. J. of Chem. Sciences 2(2) (2012) 10-17.

[27] Kumar H., Yadav V., International Letters of Chemistry, Physics and Astronomy 1 (2014) 52-66.

[28] Premkumar P., The Arab. J. Sci. Eng. 34(2C) (2009) 71.

[29] Abd S. S., Rehim E., Relay S. A. M., Saleh M. B., Ahmed R. A., J. Appl. Electrochem. 31(4) (2011) 429.

[30] Quraishi M. A., Sardar R., Jamal D., Mater. Chem. Phys.71 (3) (2001) 30.

[31] Rajappa S. K., Venkatesha T. V., Ind. J. Eng. Mater Sci. 9 (2002) 213.

[32] Quraishi M. A., Jamal D., Mater. Chem. Phys. 78(3) (2003) 608.

[33] Prabhu R. A., Shanbhag A.V., Venkatesha T. V., J. App. Electrochem. 37(4) (2007) 491.

[34] Tormoen G. W., Burket J. C., Dante J. F., Sridhar N., Tri-Service Corrosion conference, (2005). 